\title{
Heat transfer performance of R1234yf for convective boiling in horizontal micro-fin and smooth tubes
}

\author{
Thanh Nhan Phan ${ }^{1,2, *}$, Van Hung Tran ${ }^{1,2}$, Nikola Kaloyanov ${ }^{3}$, and Momchil Vassilev ${ }^{3}$ \\ ${ }^{1}$ Ho Chi Minh City University of Technology (HCMUT), 268 Ly Thuong Kiet Street, District 10, Ho \\ Chi Minh City, Vietnam \\ ${ }^{2}$ Vietnam National University Ho Chi Minh City, Linh Trung Ward, Thu Duc District, Ho Chi Minh \\ City, Vietnam \\ ${ }^{3}$ Technical University of Sofia, Power Engineering and Power Machines Department, 8 Kliment \\ Ohridski Blvd., 1000 Sofia, Bulgaria
}

\begin{abstract}
This study analyses the performance of heat transfer process which occurs in the convective boiling of Hydro fluoro Olefin (HFO) refrigerant, R1234yf, in horizontal tube. Heat transfer and pressure drop of R1234yf are analyzed and computed at the same working conditions on the same size of outer diameter of tube $d_{0}=9.52 \mathrm{~mm}$ with difference of inner surface, one is a smooth surface and microfin for other. The flow pattern maps were built at $5^{\circ} \mathrm{C}$ saturation temperature with $8.62 \mathrm{~kW} / \mathrm{m}^{2}$ of heat flux, it is presented that flow pattern of helix flow occurs at very low mass flux and low quality, while at that condition on smooth tube the flow is still stratified wavy flow. The comparison of heat transfer performance between microfin and smooth tube would be evaluated on enhancement factor $E$, penalty factor $P$ and efficiency index $I$. With the mass flux on the range $G$ $=111 \div 333 \mathrm{~kg} / \mathrm{m}^{2} \mathrm{~s}$ for $5^{\circ} \mathrm{C}$ boiling temperature, the results show that, average value of $E$ is $2.18 ; 1.45$ of $P$ and 1.54 of $I$. One more impressing thing is that, at the quality " $x$ " larger than 0.8 , the dryout phenomenon takes place on smooth tubes while microfin tubes do not have this phenomenon.
\end{abstract}

\section{Introduction}

Air conditioning and heat pump systems play an essential role in today's modern life. The size and the weight of the system are one of the most current issues. Besides, the very tough concerned of the whole World is the bad influence to the global warming potential and ozone depletion from the current refrigerants. Especially in the Kigali amendment to the Montreal Protocol held on October 15, 2016 is an agreement to reduce the consumption and production of HFCs, a wide usage of those can be witnessed in air conditioning and refrigerating industry. So that, the study about heat transfers performance for convective boiling of the HFO Refrigerant, R1234yf in horizontal microfin tubes is the interesting and

\footnotetext{
* Corresponding author: phannhan@hcmut.edu.vn
} 
important issue for manufacture and industrial market. Several studies performed investigations on boiling in horizontal smooth and microfin tubes especially for smooth tube [1-3], and for microfin tube [4-15].

Flow pattern of this type of boiling plays a significant role in the explanation of how heat transfer performance of fluids behaves. Liquid and vapor diffusion could lead to the discrepancy in flow mechanism during the phase change and therefore, to the differentiation of the characteristics of fluids. A big number of authors have drawn all their attention to the idea of defining a method to sketch out a flow pattern map of boiling process in horizontal smooth tubes of refrigerants. Until now, the issue with microfin tube is more strongly attracting with a lot of researchers around the World to complete the general flow pattern maps. Such as the method of Wojtan et al [5], Rollmann and Spindler [4], Zhuang et al [14], Yang et al [13]. In Figure 1, the flow regime of boiling in horizontal smooth tube presented by Wojtan et al [5], clearly describes the pattern of flow in each regime. In microfin tube, because of the helical structure of microfin that causes the liquid to move helically along, the patterns could be modified and classified into six regimes: annular, helix, slug/helix, stratified wavy, slug/ slug+stratified wavy and stratified flow.

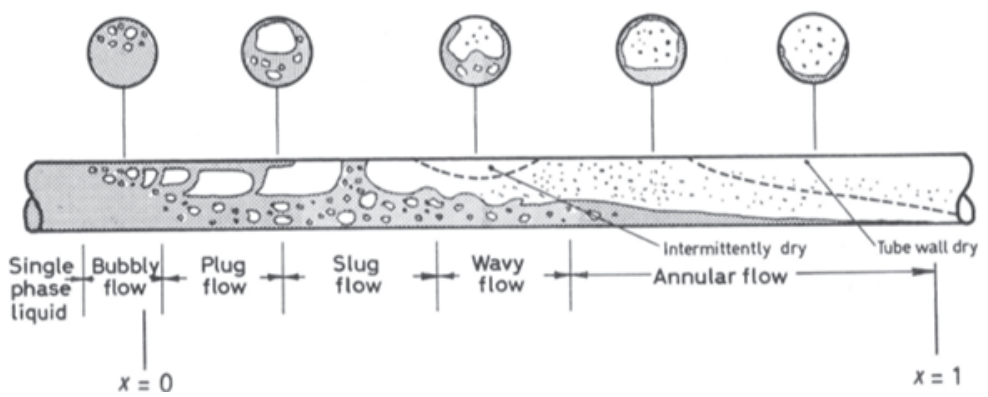

Fig. 1. Flow regime in horizontal smooth tube for boiling presented by Wojtan et al [5].

Heat transfer performance of boiling inside microfin tubes is the necessary value for designing of equipment, impacting heat transfer and pressure drop in a way that makes it drop to the size and weight of system. And also reflecting to the global issues such as ozone depletes and global warming potential which are the problem not only the caring of one person, one country but also the whole World have to hand in hand to save our planet. That is the reason why the finding out new refrigerants is the urgent and valuable task of replacement the current refrigerants. But the balance for the World and for the economy and industry is always consider, balance for the green world and balance for industry of the world. For the heat transfer coefficient of boiling in microfin tube, it is the urgent and current considered of researchers in this fields [6,8], [16-18], especially with Calvalini et al [8], they proposed the method to determine heat transfer coefficient by classification the flow boiling into nucleate boiling and forced convection and also the influence of surface geometry. With the correlation supposed by Rollmann and Spindler [6], they collected more than 1614 heat transfer measurements data on the range of saturation boiling temperature from $-30^{\circ} \mathrm{C}$ to $10^{\circ} \mathrm{C}$. The group research from Han et al [15] supported the new heat transfer coefficient correlations.

Regarding the fall of pressure, this could dramatically affect the pump load with the cause of friction factor. In the recent decades, many researchers have concentrated on the downward trend of pressure for boiling that takes place in a smooth tube and get the very good agreement with the experiment data results. Keep working with that, the continuing scientific works keep doing and moving to microfin tube and published some new correlations such as Kuo and Wang [11], Choi et al [9], Goto and Inoue [10], and WongsaNgam et al [12]. 
The study is presented the general discussion, and procedure to determine the convective boiling on microfin tube. Apply this procedure to analyze the heat transfer performance for new Refrigerant R1234yf and new microfin tube structure. To define the efficiency of microfin, the results have been compared with smooth tube.

\section{Theoretical analysis and computational method}

\subsection{The working range performance}

Geometry of microfin: The paper will explore new technologies to make novel compact, lightweight heat exchangers and to develop accurate, reliable for design and optimization of heat exchangers for a wide range of applications with the friendly refrigerant. This paper provides complex geometries for analyzing and simulation works. Detailed, the geometry of microfin tube consists of 60 number of fins on the inner surface diameter $8.96 \mathrm{~mm}$ of the tube, with $0.2 \mathrm{~mm}$ of fin height, the helix angle and apex angle are $18^{\circ}$ and $40^{\circ}$, respectively (Figure 2).

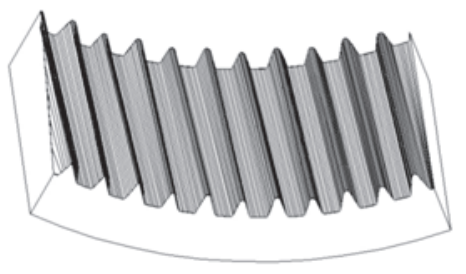

$\begin{array}{ll}\text { Microfin Tube parameter } & \text { Value } \\ \text { Outer diameter }(\mathrm{mm}) & 9.52 \\ \text { Inner diameter }(\mathrm{mm}) & 8.96 \\ \text { Fin height }(\mathrm{mm}) & 0.2 \\ \text { Fin numbers } & 60 \\ \text { Helix angle }\left(^{\circ}\right) & 18 \\ \text { Apex angle }\left({ }^{\circ}\right) & 40\end{array}$

Fig. 2. Microfin tube.

New refrigerant HFO R1234yf: On one hand, new refrigerant does not have any effect on ozone depleted ODP and global warming potential is 4, especially, the life time in atmospheric is only 11 days. It seems to be very friendly effect on the planet. On the other hand, the thermal properties of R1234yf are also good at characteristic for heat transfer. More precise, the latent heat of R1234yf at $5^{\circ} \mathrm{C}$ saturation temperature is $160 \mathrm{~kJ} / \mathrm{kg}$, with thermal conductivity of liquid phase of $0.07 \mathrm{~W} / \mathrm{mK}$ and vapor phase of $0.0121 \mathrm{~W} / \mathrm{mK}$. Those are presented in Table 1 and Table 2:

Table 1. Refrigerant R1234yf.

\begin{tabular}{|c|c|c|c|c|c|c|c|c|}
\hline Refrigerant & Components & $\begin{array}{c}\text { Safety } \\
\text { group }\end{array}$ & ODP & GWP & $\begin{array}{c}\text { Critical } \\
\text { point }\end{array}$ & $\begin{array}{c}\text { MM, } \\
\mathrm{kg} / \mathrm{kmol}\end{array}$ & NBP & $\begin{array}{c}\text { Atm. } \\
\text { lifetime }\end{array}$ \\
\hline R1234yf & HFO & A2L & 0 & 4 & $3.38 \mathrm{MPa}$ & 114.04 & $-29.5^{\circ} \mathrm{C}$ & 11 days \\
\hline
\end{tabular}

Table 2. Thermo-physical and thermodynamics properties of R1234yf at $5^{\circ} \mathrm{C}$.

\begin{tabular}{|c|c|c|c|c|c|c|c|c|}
\hline Property & $\mathbf{T}_{\text {sat }}$ & $\mathbf{L}$ & $\mathbf{v}$ & $\mathbf{L}$ & $\mathbf{v}$ & $\mathbf{c}_{\mathbf{p L}}$ & $\mathbf{c}_{\mathbf{p V}}$ & $\mathbf{h}_{\mathbf{L V}}$ \\
\hline Unit & ${ }^{\circ} \mathrm{C}$ & $\mathrm{kg} / \mathrm{m}^{3}$ & $\mathrm{~kg} / \mathrm{m}^{3}$ & $\mathrm{~m}^{3} / \mathrm{kg}$ & $\mathrm{m}^{3} / \mathrm{kg}$ & $\mathrm{kJ} / \mathrm{kgK}$ & $\mathrm{kJ} / \mathrm{kgK}$ & $\mathrm{kJ} / \mathrm{kg}$ \\
\hline R1234yf & 5 & 1160 & 20.74 & $8.62 \times 10^{-4}$ & $4.82 \times 10^{-2}$ & 1.308 & 0.948 & 160 \\
\hline Property & $\mathbf{P}_{\text {sat }}$ & $\mathbf{L}$ & $\mathbf{v}$ & $\mathbf{L}$ & $\mathbf{v}$ & $\mathbf{P r}_{\mathbf{L}}$ & $\mathbf{P r}_{\mathbf{V}}$ & \\
\hline Unit & $\mathrm{MPa}$ & $\mathrm{W} / \mathrm{mK}$ & $\mathrm{W} / \mathrm{mK}$ & $\mathrm{Pa} . \mathrm{s}$ & $\mathrm{Pa} . \mathrm{s}$ & - & - & $\mathrm{N} / \mathrm{m}$ \\
\hline R1234yf & 0.3729 & $7 \times 10^{-2}$ & $1.21 \times 10^{-2}$ & $1.97 \times 10^{-4}$ & $1.10 \times 10^{-5}$ & 3.685 & 0.891 & $8.69 \times 10^{-3}$ \\
\hline
\end{tabular}




\subsection{Data reduction}

The research works demonstrate theoretical analysis and computational simulation for building up flow pattern maps and calculate heat transfer coefficient and pressure drop of convective boiling inside microfin tube. In order to draw a map of flow mechanism, there needs to be a classification of different regimes of flow in microfin tube, which relies on flow patterns such as slug, fully stratified, stratified wavy, helix, annular and some regimes are the combination of two or three flow pattern simultaneously happened. To build the map, many parameters have been cleared about geometries of tube, heat flux, mass flux, thermo-physical and thermodynamics properties of fluid, local quality, quality change of boiling processes and define the void fraction, Martineli parameter or also estimate the shape of flow (about the liquid part and vapor part consisted on the position of tube). The procedure to build the flow pattern map for boiling in microfin tube from Rollmann and Spindler [4] modified the procedure from Wojtan et al [5] as shown below:

Transition between stratified flow and stratified wavy flow:

$$
G_{\text {strat }}=\left\{\frac{4 \mu_{L} g\left(\rho_{L}-\rho_{V}\right) \rho_{V} \varepsilon(1-\epsilon)}{S_{2} x^{2}(1-x)}\right\}^{1 / 3}+C_{5}
$$

Transition between slug flow and stratified wavy flow:

$$
\begin{gathered}
G_{\text {slug }}=\left\{\frac{16 \widetilde{A_{V}^{3}} g D \rho_{L} \rho_{V}}{x^{2} \pi^{2} \sqrt{1-\left(2 \widetilde{H_{L}}-1\right)^{2}}} C_{6}^{2}\left[\frac{4 \pi^{2}}{S_{1}^{2}{\widetilde{H_{L}}}^{2}}\left(\frac{F r}{W e}\right)_{L}+1\right]\right\}^{0.5}+C_{7} ; \\
\left(\frac{F r}{W e}\right)_{L}=\frac{\sigma}{g D^{2} \rho_{L}} ; S_{l}=5.889 ; C_{6}=1.015 ; C_{7}=-53.35 \mathrm{~kg} / \mathrm{sm}^{2},
\end{gathered}
$$

where $H_{\mathrm{L}}$ is liquid height, $\widetilde{H_{L}}=H_{L} / D$ and $\mathrm{Av}$ is gas phase area, $\widetilde{A_{V}}=A_{V} / D$.

Transition between stratified wavy flow and helix flow:

$$
\begin{gathered}
G_{S W}=\left\{\frac{16 \widetilde{A_{V}^{3}} g D \rho_{L} \rho_{V}}{x^{2} \pi^{2} \sqrt{1-\left(2 \widetilde{H_{L}}-1\right)^{2}}} C_{6}^{2}\right\}^{0.5}+C_{7}, \text { for } x \geq 0.3 ; \\
C_{6}=0.8441 ; C_{7}=0 \mathrm{~kg} / \mathrm{sm}^{2} .
\end{gathered}
$$

For $x \geq 0.3$ the transition curve in equation (3) was applied. With $\mathrm{x}<0.3$ the linear equation with the lope of transition curve from $x \geq 0.3$.

Transition between slug/helix flow and helix flow:

$$
\begin{aligned}
G_{\text {Slug-helix }} & =\left\{\frac{16 \widetilde{A_{V}^{3}} g D \rho_{L} \rho_{V}}{x^{2} \pi^{2} \sqrt{1-\left(2 \widetilde{H_{L}}-1\right)^{2}}} C_{6}{ }^{2}+C_{7} ;\right. \\
C_{6} & =1.754 ; C_{7}=-84.79 \mathrm{~kg} / \mathrm{sm}^{2} .
\end{aligned}
$$

Transition between helix flow and annular flow:

$$
\begin{gathered}
G_{\text {slug }}=\left\{\frac{16 \widetilde{A_{V}^{3}} g D \rho_{L} \rho_{V}}{x^{2} \pi^{2} \sqrt{1-\left(2 \widetilde{H_{L}}-1\right)^{2}}} C_{6}{ }^{2}\left[\frac{4 \pi^{2}}{S_{1}^{2}{\widetilde{H_{L}}}^{2}}\left(\frac{F r}{W e}\right)_{L}+1\right]\right\}^{0.5}+C_{7} ; \\
S_{1}=57.71 ; C_{6}=1.772 ; C_{7}=-25.39 \mathrm{~kg} / \mathrm{sm}^{2} .
\end{gathered}
$$

The classification of the regimes on the map:

\section{Conditions}

$\mathrm{G}<\mathrm{G}_{\text {strat }}$
Regime

Stratified flow 


$\begin{array}{ll}G>G_{\text {slug }} \text { and } G<G_{\text {sw }} & \text { Stratified wavy flow } \\ G<G_{\text {slug }} \text { and } G<G_{\text {sw }} & \text { Stratified wavy/slug flow or slug flow } \\ G<G_{\text {slug-helix }} & \text { Slug/helix flow } \\ G<G_{\text {helix }} & \text { Helix flow } \\ G>G_{\text {helix }} & \text { Annular flow }\end{array}$

\subsection{Two phases Heat transfer coefficient in boiling}

Due to the changing phase during the convective boiling, the proportion of liquid and vapor is also changed, which affected the mechanism of boiling. In order to indicate the boiling heat transfer coefficient, the nucleate boiling and convective boiling are considered as below:

Two-phase flow heat transfer coefficient:

Nucleate boiling component:

$$
\alpha=\alpha_{n b}+\alpha_{c v} .
$$

$$
\alpha_{n b}=\alpha_{\text {cooper }} S . F_{1}\left(d_{i}\right)=\left[55 P_{R}^{0.12}\left(-\log _{10} P_{R}\right)^{-0.55} M^{-0.5} q^{0.67}\right] S . F_{1}\left(d_{i}\right),
$$

where $\mathrm{F}_{1}\left(\mathrm{~d}_{\mathrm{i}}\right)$ is function of fin tip tube diameter,

Convective term:

$$
F_{1}\left(d_{i}\right)=\left(\frac{d_{o}}{d_{i}}\right)^{C}
$$

$$
\alpha_{c v}=\frac{\lambda_{L}}{d_{i}} \cdot N u_{c v, \text { smooth tube }} \cdot R x^{S} \cdot(B o . F r)^{T} \cdot F_{2}\left(d_{i}\right) \cdot F_{3}(G),
$$

where

$$
N u_{c v, \text { smooth tube }}=N u_{L O} \Phi=\left[0.023\left(\frac{G d_{i}}{\mu_{L}}\right)^{0.8} P r_{L}^{1 / 3}\right]\left[(1-x)+2.63 x\left(\frac{\rho_{L}}{\rho_{G}}\right)^{1 / 2}\right]^{0.8} \text {. }
$$

More detailed about the methodology, the boiling number and some other factors are presented in the method of each authors in Cavallini et al [8], Rollmann and Spindler [6].

\subsection{Pressure drop}

The total pressure drop is the sum of momentum pressure drop and friction pressure drop. Consider the value at the inlet and outlet of each mean value quality $x$, the assuming quality change to determine the mean value of pressure drop at local quality is calculated on the small quality change $\mathrm{d} x= \pm 0.025$. It is the meaning that at the local quality $x$, the inlet quality $x_{\mathrm{in}}=x-\mathrm{d} x$, and $x_{\mathrm{out}}=x+\mathrm{d} x$. Also, regarding the two-phase fluid and its specific volumes, when it comes to the inlet and outlet, ( $\mathrm{V}_{\mathrm{tp}, \text { out }}$ and $\mathrm{V}_{\mathrm{tp}, \mathrm{in}}$ ) these volumes are qualityweighted sums that contain those of vapor and those of liquid together.

Total pressure drop:

$$
\frac{\Delta p}{L}=\frac{\Delta p_{f}}{L}+\frac{\Delta p_{m}}{L}=G^{2}\left[f \frac{\left(v_{t p, o u t}+v_{t p, i n}\right)}{d_{h}}+\frac{\left(v_{t p, o u t}-v_{t p, i n}\right)}{L}\right] .
$$

Two phase friction factors:

$$
f=0.00506 R e_{h, L O}^{-0.0951} K_{f}^{0.1554},
$$

where

$$
R e_{h, L O}=\frac{G d_{h}}{\mu_{l}} .
$$

Two-phase number: 


$$
K_{f}=\frac{\Delta x \cdot h_{l v}}{g L} .
$$

\subsection{Data analysis procedure}

The flow pattern maps for boiling in microfin tube and smooth tube have been established based on the working conditions presented in Table 3 with the computational analysis by using Matlab code to simulate and present the maps. And then, apply those conditions to calculate the data results of convective heat transfer coefficient and pressure drop during the boiling processes.

Table 3. Working conditions.

\begin{tabular}{|c|c|c|c|c|}
\hline Tube type & Symbol & Smooth tube & Microfin tube & Unit \\
\hline Refrigerant & R & R1234yf & R1234yf & - \\
\hline Boiling temperature & T & 5 & 5 & ${ }^{\circ} \mathrm{C}$ \\
\hline Outer diameter & Do & 9.52 & 9.52 & $\mathrm{~mm}$ \\
\hline Inner diameter & Di & 8.92 & 8.96 & $\mathrm{~mm}$ \\
\hline Area cross & A & 62.491 & 62.183 & $\mathrm{~mm}^{2}$ \\
\hline Perimeter & P & 28.023 & 44.4 & $\mathrm{~mm}$ \\
\hline Mass flux & G & $111 ; 222 ; 333$ & $111 ; 222 ; 333$ & $\mathrm{~kg} / \mathrm{m}^{2} \mathrm{~s}$ \\
\hline Heat flux & q & 8.62 & 8.62 & $\mathrm{~kW} / \mathrm{m}^{2}$ \\
\hline
\end{tabular}

\section{Comparison Parameters between microfin tube and smooth tube}

With a view to comparing the performance of two-phase flows that move between a microfin tube and a smooth tube, there needs to be an introduction of some indexes, namely enhancement factor, penalty factor and efficiency index factor, which are explained as below:

Enhancement factor:

$$
E=\frac{h_{m f}}{h_{s}},
$$

where $\mathrm{E}$ is enhancement factor, [-];

$\mathrm{h}_{\mathrm{mf}}-$ microfin tube heat transfer coefficient, $\mathrm{W} / \mathrm{m}^{2} \mathrm{~K}$;

$\mathrm{h}_{\mathrm{s}}$ - smooth tube heat transfer coefficient, $\mathrm{W} / \mathrm{m}^{2} \mathrm{~K}$.

Penalty factor:

$$
P=\frac{\left(\frac{\Delta p}{L_{p}}\right)_{m f}}{\left(\frac{\Delta p}{L_{p}}\right)_{s}},
$$

where $\mathrm{P}$ is penalty factor, [-];

$\left(\frac{\Delta \mathrm{p}}{\mathrm{L}_{\mathrm{p}}}\right)_{\mathrm{mf}}$ - microfin tube pressure drop per unit length, $\mathrm{Pa} / \mathrm{m}$;

$\left(\frac{\Delta \mathrm{p}}{\mathrm{L}_{\mathrm{p}}}\right)_{\mathrm{s}}$ - smooth tube pressure drop per unit length, $\mathrm{Pa} / \mathrm{m}$. 
Efficiency index:

where $\mathrm{I}$ is efficiency index, [-].

$$
I=\frac{E}{P}
$$

\section{Results and discussion}

\subsection{Flow pattern maps}

Applying the new method from Rollmann and Spindler [4], the simulation procedure was done by using Matlab code to draw a map for microfin tube and also done for smooth tube based on procedure of Wojtan et al [5]. With the input parameters presented in Table 3, the boiling temperature is $5^{\circ} \mathrm{C}$, heat flux is $8.62 \mathrm{~kW} / \mathrm{m}^{2}$, the flow pattern map was created for smooth tube at $8.92 \mathrm{~mm}$ inner diameter and $8.96 \mathrm{~mm}$ inner diameter for microfin tube with 60 fins, $0.2 \mathrm{~mm}$ fin height, $18^{\circ}$ of helix angle and $40^{\circ}$ of apex angle.

The results shown in Figure 3 and Figure 4 with the maps of flow pattern in microfin tube and smooth tube were built at working conditions in Table 3 . It could be clarified with horizontal exes expresses the quality $x$ from 0 to 1 and vertical axes of mass flux $\mathrm{G}, \mathrm{kg} / \mathrm{m}^{2} \mathrm{~s}$.

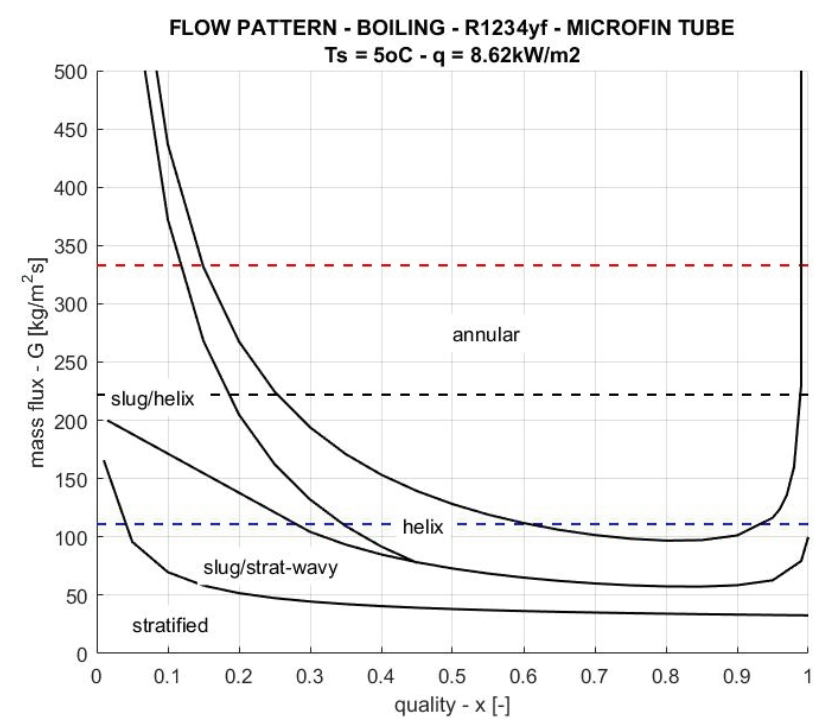

Fig. 3. Flow pattern map - microfin tube.

The flow patterns map for microfin tube in Figure 3 presents the regions of each flow regimes: stratified, slug/stratified wavy, slug/helix, helix and annular. Figure 4 shows the map for smooth tube, expressing the regimes on stratified, slug, slug/stratified wavy, stratified wavy, intermittent, annular, dryout and mist flow. In order to deeply understand the map, take the mass flux $\mathrm{G}=333 \mathrm{~kg} / \mathrm{m}^{2} \mathrm{~s}$ as a typical example, on the microfin tube, when the boiling process with quality less than $0.12(x<0.12)$ the pattern of flow is slug/helix flow, and keep boiling with the increasing of quality to the range $0.12<x<0.15$ the flow regime move to the helix flow and after that, annular flow for the rest of quality $(x$ $>0.15)$. 


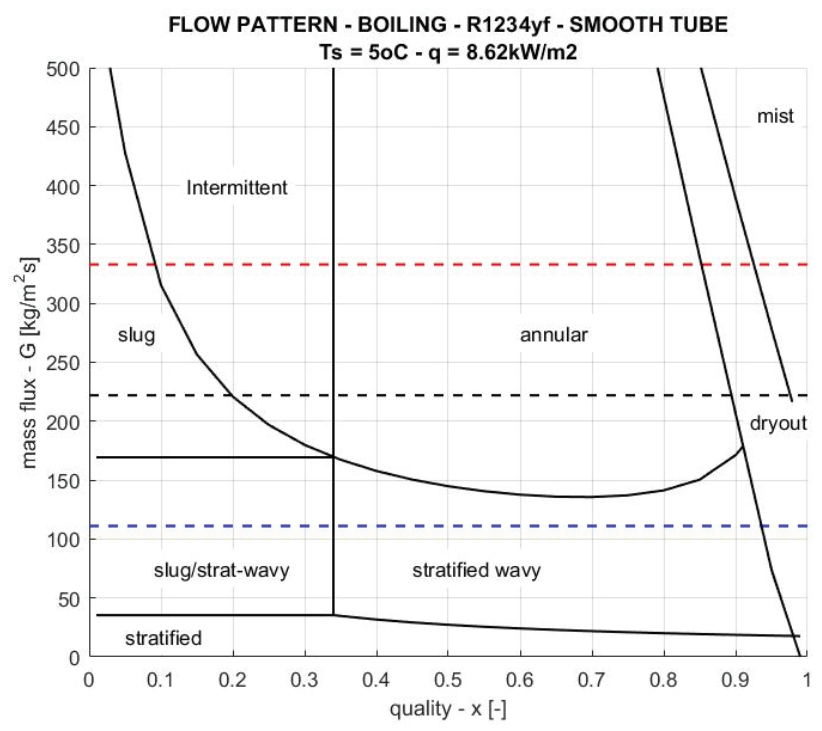

Fig. 4. Flow pattern map - smooth tube.

Compare at the same mass flux $\mathrm{G}=333 \mathrm{~kg} / \mathrm{m}^{2} \mathrm{~s}$ with smooth tube, when the boiling happen with quality $x<0.09$, pattern of flow is slug, $0.09<x<0.34$ is the range of Intermittent flow and $0.34<x<0.85$ annular flow always occurs and then dryout happen on the range of $0.85<x<0.92$, with $x>0.92$ is the mist flow. It could be recognized that the annular flow on microfin tube with quality $x>0.15$ but on the smooth tube, the annular flow just only be occurred on the shorter ranges $0.34<x<0.85$. Based on the difference of flow pattern due to the influenced of microfin to create the turbulent and helixation flow of refrigerant, the helix flow occurs and lets to the annular flow happened sooner than smooth tube at the same working range of mass flux.

\subsection{Heat transfer coefficients}

This is the estimated data results for boiling R1234yf in microfin tube. Due to not so many research focuses on the newest refrigerants and newest microfins, the mean analysis method is applied to analyze data results. The method is to apply the available correlations about heat transfer coefficient in microfin tube and using the Matlab to solve the result at the working condition in Table 3 above. With each correlation, each data point can get, the mean value is the average value of all data points at the same working condition which was solved on correlations. If the error of any correlation value is larger than $30 \%$ comparing the mean value with the majority of value correlations, that correlation would be eliminated. So that the data analysis results presented in this paper is the mean value from the analysis of available correlations.

Heat transfer coefficients in the working range on Table 3 at $5^{\circ} \mathrm{C}$ saturation temperature, mass flux from $111 \mathrm{~kg} / \mathrm{m}^{2} \mathrm{~s}$ to $333 \mathrm{~kg} / \mathrm{m}^{2} \mathrm{~s}$ on the range of quality $x$ from 0.05 to 0.95 have been done by applying some general correlations for convective boiling in microfin tube. So many general correlations for this problems such as Cavallini et al [8], $\mathrm{Yu}$ et al [18], Yun et al [16], Chamra and Mago [19], Rollmann and Spindler [6], Han et al [15], in this paper, after reviewed the wide range of application for each correlations and resolved some first data to classify and eliminate some correlations with data result is too large error compare with the mean values. At the end, the chosen correlations were used is Cavallini et al [8], Yun et al [16], Rollmann and Spindler [6], and Han et al [15]. Besides, 
the data results of heat transfer coefficient on smooth tube for boiling of R1234yf at $5^{\circ} \mathrm{C}$ were done on the previous published of our group research, those were detailing presented in [1-3].

As shown in the Figure 5, the mean value of heat transfer coefficients for convective boiling of R1234yf at $5^{\circ} \mathrm{C}$ with heat flux $8.62 \mathrm{~kW} / \mathrm{m}^{2}$ are represented for various mass flux $\mathrm{G}=111 ; 222$ and $333 \mathrm{~kg} / \mathrm{m}^{2} \mathrm{~s}$ with smooth and microfin tube.

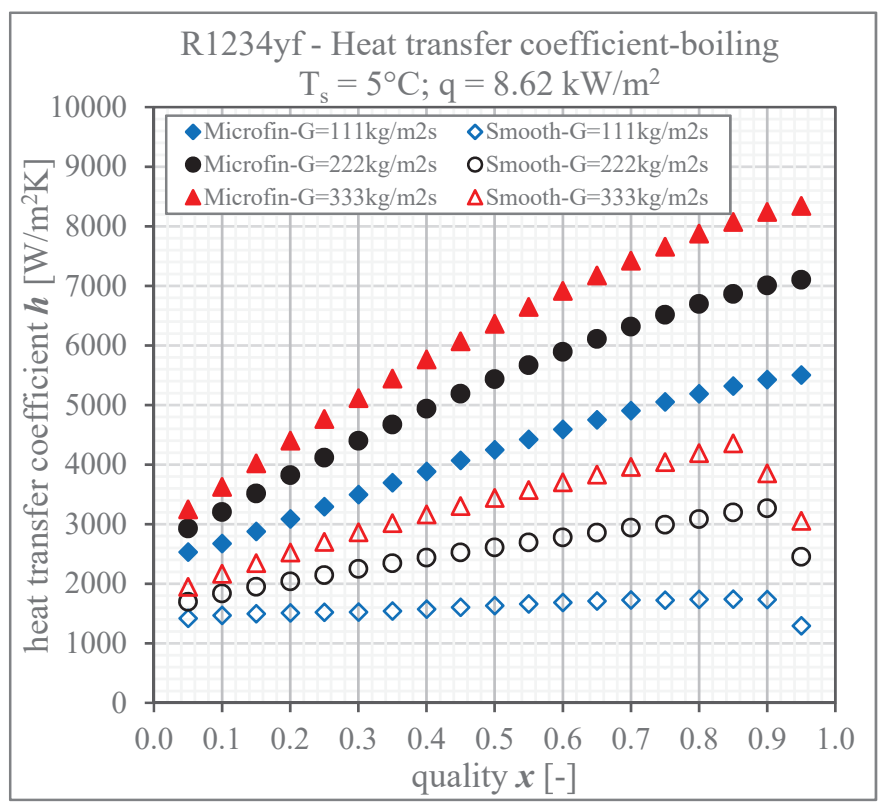

Fig. 5. Heat transfer coefficient for microfin and smooth tube.

It is obviously observed that higher mass flux, higher heat transfer coefficient can be achieved for both smooth and also microfin tube. The heat transfer coefficient obtained on microfin tube is always higher than smooth tube at the same mass flux. The structure of microfin inside the tube could be a factor to blame for this, thanks to the microfin with the spiral of the fins could led the liquid phase of refrigerant at the lower part of the tube reach to higher position and some case can be reached to the top of the tube and create the wet surface inside of the tube. Clearer, the explanation by using the flow pattern map for microfin tube in Figure 3, the helix flow appears very soon at low quality while for smooth tube do not have this pattern.

Another impressive result obtained in this research is the fact that heat transfer coefficient went up continuously in microfin tube from low quality to high quality with no disruptive drop at any range of quality while in the case of a smooth tube, this coefficient is reduced and went down dramatically at some moments of high quality. Regarding the smooth tube, dryout phenomenon occurred in the determined quality of flow, as observed in Figure 4. At the mass flux $\mathrm{G}=333 \mathrm{~kg} / \mathrm{m}^{2} \mathrm{~s}$, the dryout process took place when the quality is 0.85 , and as a result, in Figure 5, the heat transfer coefficient could be witnessed, also at quality 0.85 . It can be concluded that the dryout phenomenon was possibly the reason and it was an unexpected thing of flow regime; thus, with the advantage of microfin tube, this problem could be solved.

As described in more details in Figure 6, when $\mathrm{G}=222 \mathrm{~kg} / \mathrm{m}^{2} \mathrm{~s}$, heat transfer coefficient in microfin tube are almost twice higher than sin smooth tube, and the dryout is observed at $x=0.9$. 


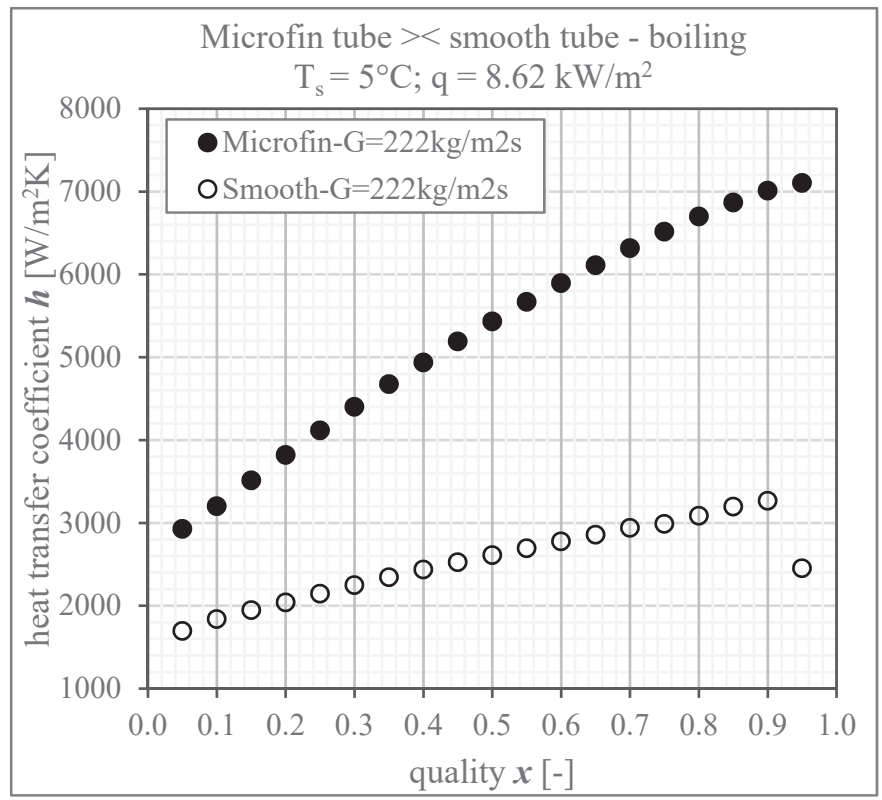

Fig. 6. Heat transfer coefficient at $\mathrm{G}=222 \mathrm{~kg} / \mathrm{m}^{2} \mathrm{~s}$.

\subsection{Pressure drop}

Analyzing for the pressure drop, mean value of pressure drop is a result of computing the pressure drop with the chosen correlations of Kuo and Wang [11], Choi et al [9], Goto and Inoue [10], and Wongsa-Ngam et al [12]. In Figure 7, the mass flux is the main affected on the increasing of the pressure drop not only for smooth tube but also for microfin tube.

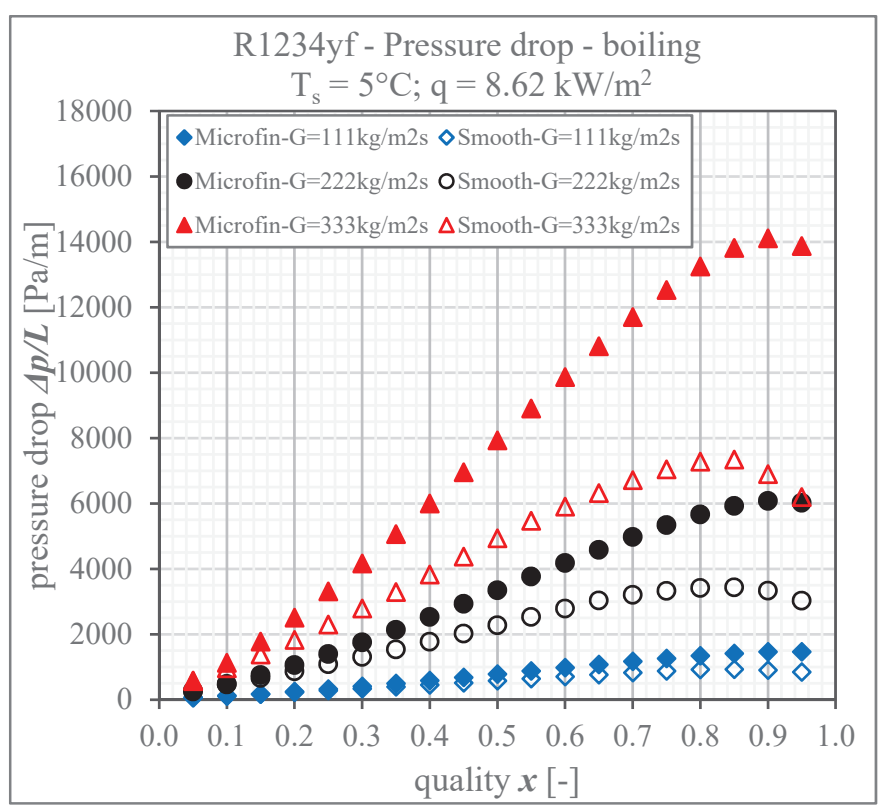

Fig. 7. Pressure drop for microfin and smooth tube. 
In Figure 8, the comparison between microfin tube and smooth tube of pressure drop at mass flux $222 \mathrm{~kg} / \mathrm{m}^{2} \mathrm{~s}$, is the confirmation about the influence of microfin in the surface that could be the increasing of friction factor and rising of pressure drop.

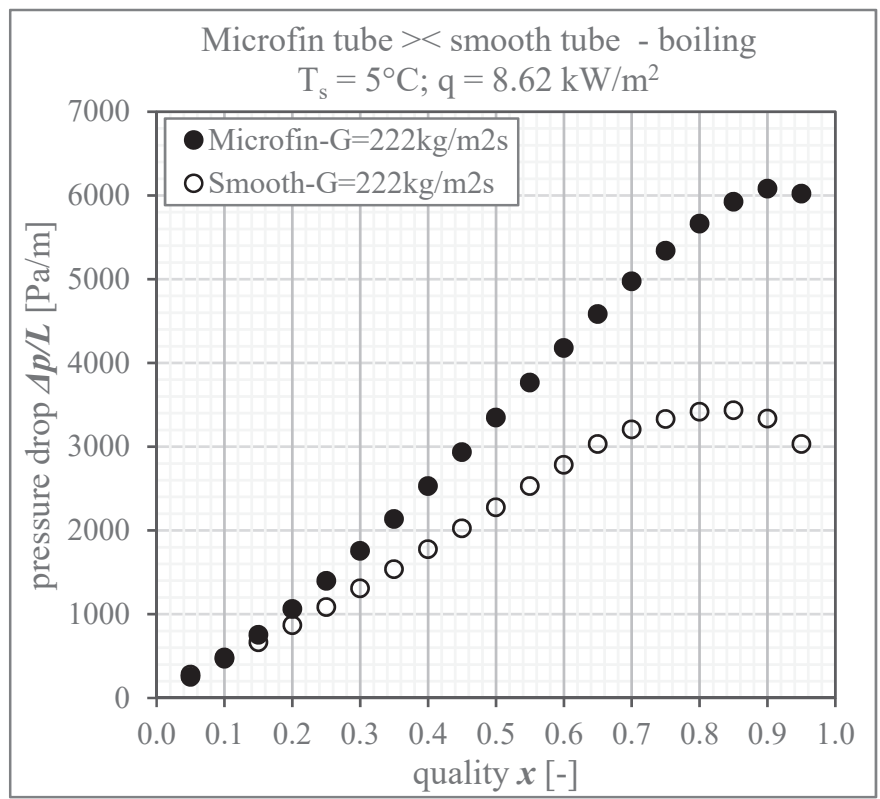

Fig. 8. Pressure drop at $\mathrm{G}=222 \mathrm{~kg} / \mathrm{m}^{2} \mathrm{~s}$.

\subsection{Enhancement factor E, Penalty factor P and Efficiency Index I}

Analyzing the value of Enhancement factor E, Penalty factor P and Efficiency Index I is to define the efficiency of microfin tube comparing with smooth tube. Data results show that, the enhancement factor is from 1.7 to 3 times while the penalty factor is on the range of 1 to 1.8 times which is defined on the whole range of quality $x$ and mass flux G. For general, in Table 4 it is shown that the lower mass flux $G$ the higher enhancement factor $E$ and converted with the penalty factor P. About the efficiency index I, the mass fluxes were considered at $111 \mathrm{~kg} / \mathrm{m}^{2} \mathrm{~s}, 222 \mathrm{~kg} / \mathrm{m}^{2} \mathrm{~s}$ and $333 \mathrm{~kg} / \mathrm{m}^{2} \mathrm{~s}$, the average efficiency index I is 2 , 1.45 and 1.18, respectively. It means at the low mass flux, the valuable of microfin tube is more impressive than at higher mass flux. At the end, on this working ranges, the average value of $\mathrm{I}$ is around 1.54 .

Table 4. Comparison between microfin tube and smooth tube.

\begin{tabular}{|c|c|c|c|}
\hline \multirow{2}{*}{$\begin{array}{c}\text { Convective boiling }-\mathbf{R 1 2 3 4 y f} \\
\mathbf{T}_{\mathbf{s}}=\mathbf{5}^{\circ} \mathbf{C} ; \mathbf{q}=\mathbf{8 . 6 2} \mathbf{~ k W} / \mathbf{m}^{2}\end{array}$} & Enhancement factor & Penalty factor & Efficiency Index \\
\cline { 2 - 4 } & $\mathbf{E}=\mathbf{h}_{\mathbf{m f}} / \mathbf{h}_{\mathbf{s}}$ & $\mathbf{P}=\mathbf{p}_{\mathbf{m f}} / \mathbf{p}_{\mathbf{s}}$ & $\mathbf{I}=\mathbf{E} / \mathbf{P}$ \\
\hline $\mathrm{G}=111 \mathrm{~kg} / \mathrm{m}^{2} \mathbf{s}$ & 2.60 & 1.30 & 2.00 \\
\hline $\mathrm{G}=222 \mathrm{~kg} / \mathrm{m}^{2} \mathrm{~s}$ & 2.06 & 1.45 & 1.45 \\
\hline $\mathrm{G}=333 \mathrm{~kg} / \mathrm{m}^{2} \mathrm{~s}$ & 1.87 & 1.61 & 1.18 \\
\hline AVERAGE & 2.18 & 1.45 & 1.54 \\
\hline
\end{tabular}




\section{Conclusion}

A computational method combined with Matlab to build flow pattern maps for convective boiling in microfin tube and smooth tube of new refrigerant R1234yf have been done. The effectiveness of heat transfer performance under the Efficiency index I which is compared between the value of enhancement factor and penalty factor are introduced. Based on the average value of efficiency index for the whole working ranges of boiling in this paper I = 1.54 , the conclusion could be obtained which is the valuable replacement of microfin tubes and smooth tubes with the friendly refrigerant R1234yf on the heat exchanger evaporators.

We would like to thank The Ho Chi Minh City University of Technology (HCMUT), VNU-HCM for the support of time and facilities for this study.

\section{References}

1. T.N. Phan, V.H. Tran, P.H. Huynh, N. G. Kaloyanov, M. P. Vasilev, XXIV Scientific Conference with International Participation FPEPM, Sozopol, pp. 108-115, (2019).

2. T.N. Phan, V.H Tran, P.H. Huynh, N. G. Kaloyanov, M. P. Vasilev, XXIV Scientific Conference with International Participation FPEPM, Sozopol, pp. 99-107, (2019).

3. T.N. Phan, V.H. Tran, P.H. Huynh, N. G. Kaloyanov, M. P. Vasilev, XXIV Scientific Conference with International Participation FPEPM, Sozopol, pp. 116-123, (2019).

4. P. Rollmann, K. Spindler, Int. J. Multiph. Flow, 72, pp. 181-187, (2015).

5. L. Wojtan, T. Ursenbacher, J. R. Thome, Int. J. Heat Mass Transf., 48(14), pp. 2955 2969, (2005).

6. P. Rollmann, K. Spindler, Int. J. Therm. Sci., 103, pp. 57-66, (2016).

7. D. Han, K. J. Lee, Int. J. Heat Mass Transf., 48(18), pp. 3804-3816, (2005).

8. A. Cavallini, D. Del Col, L. Doretti, G. A. Longo, L. Rossetto, Int. J. Heat Technol., 17(2), pp. 29-36, (1999).

9. J. Y. Choi, M. A. Kedzierski, P. A. Domanski, Proc. of IIF-IIR Commision B1, Paderborn - GE, B4 pp. 9-16, (2001).

10. N. I. M. Goto, N. Inoue, Int. J. Refrig., 24(1), pp. 528-538, (2001).

11. C. S. Kuo, C. C. Wang, Int. J. Heat Mass Transf., 39(12), pp. 2559-2569, (1996).

12. J. Wongsa-Ngam, T. Nualboonrueng, S. Wongwises, Int. J. Heat Mass Transf., 40(6), pp. 425-435, (2004).

13. Z. Q. Yang et al., Int. J. Multiph. Flow, 98, pp. 24-35, (2018).

14. X. Zhuang, M. Gong, G. Chen, X. Zou, J. Shen, Int. J. Heat Mass Transf., 102, pp. 1141-1149, (2016).

15. X. H. Han, Y. B. Fang, M. Wu, X. G. Qiao, G. M. Chen, Int. J. Heat Mass Transf., 104, pp. 276-287, (2017).

16. R. Yun, Y. Kim, K. Seo, H. Young Kim, Int. J. Heat Mass Transf., 45(10), pp. 20032010, (2002).

17. Z. Wu, Y. Wu, B. Sundén, W. Li, Exp. Therm. Fluid Sci., 44, pp. 398-408, (2013).

18. M. Yu, T. Lin, C. Tseng, Int. J. Refrig., 25(6), pp. 789-798, (2002).

19. L. M. Chamra, P. J. Mago, Proc. Inst. Mech. Eng. C J. Mech. Eng. Sci., 221(4), pp. 443-447, (2007). 